\title{
Políticas públicas e voz do professor: caracterização das leis brasileiras
}

\section{Public policy and teachers' voice: characterization of Brazilian laws}

\author{
Léslie Piccolotto Ferreira ${ }^{1}$, Emilse Aparecida Merlin Servilha², Maria Lúcia Vaz Masson³, \\ Micheline Baldini de Figueiredo Maciel Reinaldi ${ }^{4}$
}

\begin{abstract}
RESUMO
Objetivo: Caracterizar as leis sobre saúde vocal publicadas em todo território nacional até o ano de 2006. Métodos: Foram feitas buscas da documentação em sites oficiais, assim como um questionário elaborado pelas autoras foi divulgado no meio fonoaudiológico, por correio eletrônico, para captar o maior número de leis possível. Obtiveram-se 22 documentos que foram analisados quanto ao raio de abrangência, ações propostas, natureza dessas ações, público-alvo, secretarias envolvidas, iniciativa e promulgação das leis. Tais dados foram analisados de maneira absoluta (numérica) e relativa (percentualmente). Resultados: Os documentos são, em sua maioria, leis de abrangência estadual, mais numerosas na região sudeste, propostas pelo poder legislativo, cuja viabilização compete a uma parceria entre secretarias de saúde e educação estaduais. As ações propostas, de modo geral, preconizam a implementação de assistência preventiva por meio de cursos teórico-práticos (90,91\%), com periodicidade anual, ministrados por fonoaudiólogos, com a ressalva de que será oferecido, ao professor com distúrbio vocal, acesso ao tratamento fonoaudiológico e/ou médico (77,27\%). Em apenas três documentos $(13,64 \%)$ avança-se para além de cursos, com propostas de ações de promoção à reabilitação, inclusive com menção ao ambiente de trabalho. Dois deles $(9,09 \%)$ consideram os direitos do professor trabalhador. Conclusão: Levando-se em conta o grande número de casas legislativas no Brasil, poucas são as leis propostas a favor da saúde do professor, especialmente em relação à voz. Além disso, para que sejam aplicadas e transformadas em programas de saúde vocal, tais iniciativas devem partir de competência constitucional própria, a fim de garantir os recursos financeiros necessários para a sua viabilização.
\end{abstract}

Descritores: Docentes; Leis; Promoção de saúde; Prevenção de doenças; Políticas públicas de saúde; Legislação sanitária; Legislação

\section{INTRODUÇÃO}

Em seus primórdios, a Fonoaudiologia tinha um caráter eminentemente de reabilitação e dessa forma todas as suas ações constituíam-se em propostas na direção da "cura" dos chamados distúrbios da comunicação. Tal atuação não era

Trabalho realizado em conjunto pelas instituições: Pontifícia Universidade Católica de São Paulo - PUC-SP - São Paulo (SP), Brasil; Pontifícia Universidade Católica de Campinas - PUCCamp - Campinas (SP), Brasil; e Universidade Federal da Bahia - UFBA - Salvador (BA), Brasil.

Nota do editor: $O$ artigo foi publicado eletronicamente como nota prévia no endereço: http://www.sbfa.org.br/portal/voz_profissional/leis.pdf.

(1) Doutora, Professora Titular do Departamento de Fundamentos da Fonoaudiologia da Pontifícia Universidade Católica de São Paulo - PUC-SP - São Paulo (SP), Brasil.

(2) Doutora, Professora Titular da Faculdade de Fonoaudiologia da Pontifícia Universidade Católica de Campinas - PUCCamp - Campinas (SP), Brasil.

(3) Pós-graduanda em Educação pela Universidade Estadual Paulista, Campus de Marília - UNESP - Marília (SP), Brasil; Professora assistente do Departamento de Fonoaudiologia da Universidade Federal da Bahia - UFBA - Salvador (BA), Brasil.

(4) Especialista em Audiologia; Assessora parlamentar do Conselho Federal de Fonoaudiologia - CFFa - Brasília (DF) Brasil.

Endereço para correspondência: Léslie Piccolotto Ferreira. R. Jesuíno Bandeira, 73, São Paulo - SP, CEP 05048-080. E-mail: lesliepf@ pucsp.br Recebido em: 7/1/2008; Aceito em: 21/7/2008 diferente entre os profissionais que atuavam com os problemas de voz.

Ao final da década de 70 e início de 80 , no século passado, foi possível enveredar, mesmo que timidamente, pelas vertentes da promoção de saúde e prevenção de alterações vocais, com foco mais direcionado principalmente à escola ${ }^{(1)}$.

Nesse contexto, o fonoaudiólogo que atuava na área de voz deu maior atenção ao professor, que de todos os chamados profissionais da voz, são, até hoje, os mais presentes na clínica e os mais pesquisados ${ }^{(2-3)}$, seguidos pelos teleoperadores, com registro das primeiras atuações datadas de $1987^{(4)}$.

O adoecimento vocal, principalmente do professor, é explicitado em pesquisas nacionais ${ }^{(5-10)}$ e internacionais ${ }^{(11-17)}$ como fruto de interferência de dois gêneros de fatores. Os primeiros são os fatores ambientais como o ruído, a poeira, a fumaça. Os fatores organizacionais evidenciados no excesso de trabalho, cobrança excessiva e falta de material, apenas para citar alguns. Ambos se associam ao despreparo vocal desse profissional, que se vê imerso em contexto desfavorável, sem ter conhecimento de como reverter a situação.

A docência é usualmente relacionada ao estresse elevado, secundário à organização do trabalho e seus riscos, que juntos geram ou agravam distúrbios vocais e comprometimento da saúde mental ${ }^{(18)}$. 
Além desses fatores, outros inerentes ao próprio sujeito, são considerados inimigos biológicos da voz. São eles as alterações advindas com a idade, alergias, infecções de vias aéreas superiores, influências hormonais, medicações, etilismo, tabagismo e falta de hidratação ${ }^{(19)}$.

Entretanto, vale ressaltar que o achado de uma alteração de natureza pessoal, não descarta a existência concomitante de um distúrbio de voz relacionado ao trabalho, segundo o documento encaminhado para ser incluído no Manual de Doenças Relacionadas ao Trabalho e ao Instituto Nacional do Seguro Social ${ }^{(18)}$.

Os sintomas do distúrbio de voz têm início insidioso, com predominância no final do dia de trabalho e piora no decorrer da semana e do semestre letivo. Após descansos noturnos, finais de semana e férias, a voz tende a melhorar. Contudo, aos poucos, tais sintomas se apresentam continuamente e sem expectativa de melhora. Os mais comuns são: rouquidão, fadiga vocal, ardor e/ou dor na região da garganta e pescoço, dificuldade em manter a voz, variações na frequência fundamental, falta de volume e projeção vocal, perda na eficiência vocal, pouca resistência ao falar e afonia ou perda total da $\mathrm{voz}^{(18)}$.

Todos esses aspectos têm, nos últimos anos, mobilizado políticos, representantes da população, no encaminhamento de projetos de lei. Esses procuram garantir ações de prevenção que objetivam diminuir a incidência de alterações vocais nos professores. Alguns fonoaudiólogos, principalmente os que atuam na área da Saúde Pública, fazem restrição ao uso do termo "saúde vocal", por considerarem que a saúde deve ser entendida como um todo indissociável e não segmentada, de modo à nunca se perder de vista a integralidade do sujeito ${ }^{(20)}$. Apesar de haver concordância com tal restrição, optou-se pela utilização desta nomenclatura, pois ela é recorrente no título ou no conteúdo de todas as leis analisadas e por se tratar de um termo consagrado na área fonoaudiológica.

A redação de qualquer projeto de lei apresenta duas partes básicas: a primeira é o texto da lei propriamente dita, que traduz a idéia que o político propõe; a segunda é sua justificativa. Nesta última, o proponente deve explicar a razão de sua apresentação, acompanhada da necessidade e importância, momento em que conclama os demais parlamentares a votar favoravelmente a sua proposta (http://www.al.sp.gov.br). Quando aprovado, o projeto de lei é encaminhado ao chefe do poder executivo que, ao sancioná-lo e o promulgar, o transforma em lei, devendo, em período determinado, ser colocado em prática. Este parece ser o momento mais difícil, pois a maioria dessas leis acaba por não ser aplicada, não se concretizando de fato.

A pouca divulgação da legislação existente no Brasil, sobre questões vocais, mobilizou esta pesquisa que tem como objetivo caracterizar as leis sobre saúde vocal publicadas em todo território nacional. Os resultados encontrados poderão subsidiar novos projetos, assim como fundamentar ações políticas que levem os aprovados a serem definitivamente implementados.

\section{MÉTODOS}

O material para o presente estudo constou de um levantamento de leis que versavam sobre saúde vocal. A identificação desse material iniciou-se com pesquisas em sites de assembléias legislativas, câmaras municipais, governos estaduais e prefeituras. Além disso, um questionário foi elaborado pelas autoras e distribuído na comunidade fonoaudiológica com intuito de obter informações desses profissionais sobre o conhecimento das leis em questão.

O período estabelecido compreendeu desde a primeira referência, em 1998, até o final do ano de 2006.

Os documentos foram organizados em uma planilha construída para tal fim, destacando-se o número, ano, região, esfera de governo em que a lei foi apresentada, tipo e natureza das ações propostas, população-alvo, iniciativa, promulgação e secretarias do governo envolvidas. Tais dados foram analisados de maneira absoluta (numérica) e relativa (percentualmente).

\section{RESULTADOS}

O conjunto de 22 documentos obtidos é constituído de uma lei complementar (464/2002), e outras 21 leis ordinárias. Constatou-se que a primeira lei ordinária sobre saúde vocal foi proposta pelo Município de Diadema em São Paulo e data de 1998. Das leis analisadas, 59,09\% foram aprovadas nos últimos cinco anos, de 2002 a 2006 (Quadro 1).

A distribuição das leis de acordo com seu proponente,

Quadro 1. Apresentação das leis segundo número/ano, data de promulgaçãoe ente federativo promulgador $(n=22)$

\begin{tabular}{|c|c|c|c|}
\hline & Número/ano & Data & Ente promulgador \\
\hline 1 & $1.652 / 98$ & $14 / 04 / 1998$ & Diadema/SP \\
\hline 2 & $1781 / 99$ & 08/07/1999 & Santos/SP \\
\hline 3 & $7.878 / 99$ & 02/09/1999 & Santo André/SP \\
\hline 4 & $3.435 / 00$ & $17 / 04 / 2000$ & Jaú/SP \\
\hline 5 & $2.198 / 00$ & 20/12/2000 & MS \\
\hline 6 & $12.046 / 01$ & $17 / 07 / 2001$ & PE \\
\hline 7 & $6.776 / 01$ & 26/09/2001 & ES \\
\hline 8 & $10.893 / 01$ & 28/09/2001 & SP \\
\hline 9 & $1.992 / 01$ & $13 / 12 / 2001$ & Santos/SP \\
\hline 10 & $5.845 / 02$ & 04/06/2002 & Guarulhos/SP \\
\hline 11 & $464 / 02$ & $11 / 10 / 2002$ & $\begin{array}{l}\text { Santos/SP } \\
\text { (complementar)* }^{*}\end{array}$ \\
\hline 12 & $3.220 / 03$ & 05/11/2003 & DF \\
\hline 13 & $8.014 / 03$ & $28 / 11 / 2003$ & MT \\
\hline 14 & $13.778 / 04$ & $11 / 02 / 2004$ & São Paulo/SP \\
\hline 15 & $1.560 / 04$ & $26 / 02 / 2004$ & $A C$ \\
\hline 16 & $6.584 / 04$ & $14 / 06 / 2004$ & Maringá/PR \\
\hline 17 & $3.352 / 04$ & $10 / 09 / 2004$ & Teresina/PI \\
\hline 18 & $2.980 / 05$ & 29/09/2005 & AM \\
\hline 19 & $14.939 / 05$ & $14 / 12 / 2005$ & PR \\
\hline 20 & $91355 / 06$ & 05/01/2006 & Belo Horizonte/MG \\
\hline 21 & $5548 / 06$ & 23/01/2006 & PI \\
\hline 22 & $16.077 / 06$ & $26 / 04 / 2006$ & MG \\
\hline
\end{tabular}

* A lei 464/02 é a única complementar. Todas as outras são ordinárias. 


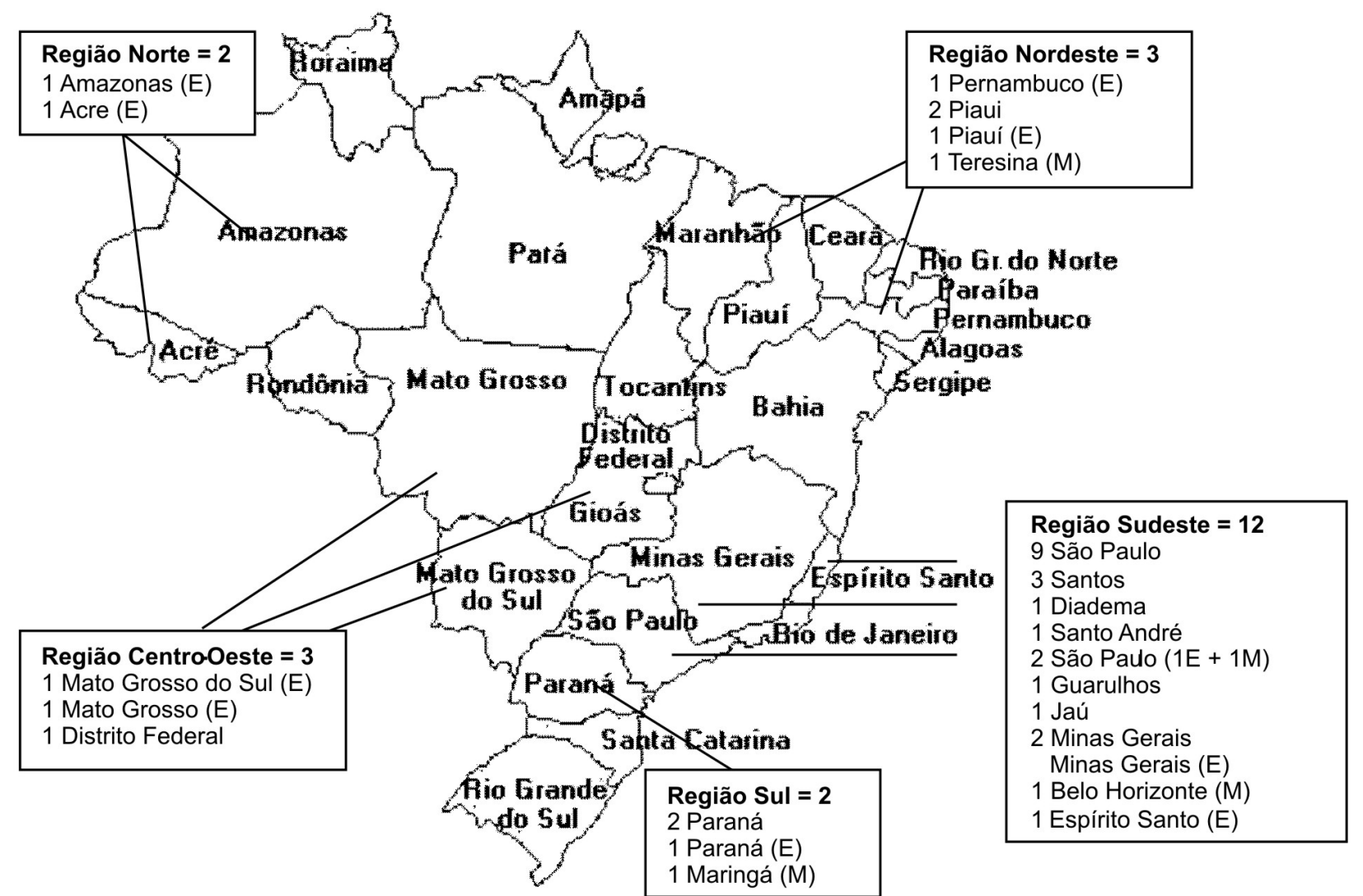

Figura 1. Distribuição das leis, segundo região, estado e/ou município proponente ( $n=22)$

Tabela 1. Distribuição numérica das leis, segundo esfera de governo e região geográfica $(n=22)$

\begin{tabular}{lcc}
\hline Esfera de governo & $\mathrm{n}$ & $\%$ \\
\hline Municipal & 11 & 50,00 \\
Estadual & 10 & 45,45 \\
Distrito Federal & 1 & 4,55 \\
Região geográfica & & \\
Sul & 2 & 9,09 \\
Sudeste & 12 & 54,55 \\
Centro-Oeste & 3 & 13,64 \\
Nordeste & 3 & 13,64 \\
Norte & 2 & 9,09 \\
\hline
\end{tabular}

considerando região, estado e distrito federal é apresentada na Tabela 1 e Figuras 1 e 2.

Evidencia-se a presença de mais da metade do total na Região Sudeste $(54,55 \%)$, com maior concentração no estado de São Paulo $(40,91 \%)$. Todas as propostas evidenciam tratar-se de um programa, e dessa forma, apresentam caráter mais abrangente. Exceção feita às iniciativas do Município de Santo André/SP (7878/1998), que em sua ementa propõe uma Campanha de Saúde Vocal e tem, portanto, caráter mais transitório, e a de Minas Gerais, que estabelece uma Política de Saúde Vocal (16077/2006) de maior amplitude.

De modo geral, os documentos apresentam bastante similaridade textual quanto ao objetivo e ações propostas, talvez pelos mais antigos terem servido de base para os mais recen-

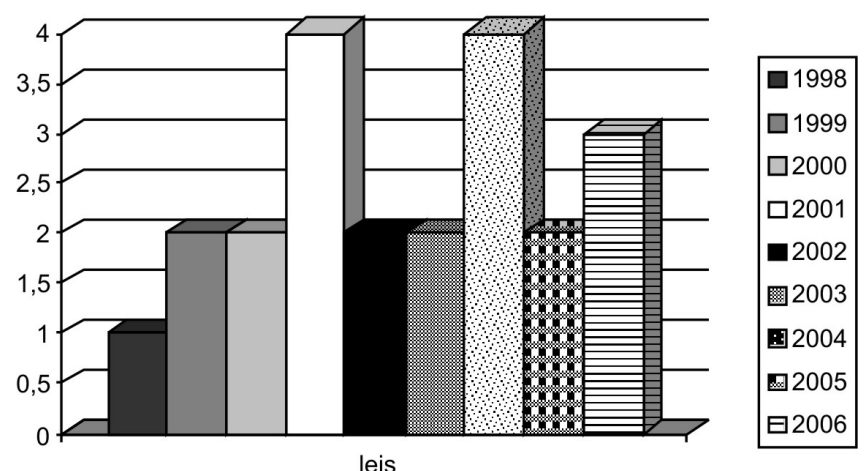

Figura 2. Número de leis aprovadas no período de 1998 a 2006

tes. A Tabela 2 evidencia que o objetivo das proposituras é a assistência preventiva, realizada por meio de cursos $(90,91 \%)$, com periodicidade anual e do tipo teórico-prático realizados no início do ano, junto ao planejamento escolar e ainda para aqueles que iniciam a carreira como professor. Palestras $(31,82 \%)$ e outras modalidades de ação como treinamentos $(18,18 \%)$ e exames admissionais e periódicos $(18,18 \%)$ são referidos como estratégias de prevenção de distúrbios vocais no professor, contudo em número menor.

Apesar de destacar o caráter preventivo das proposituras, além das ações mencionadas, em 77,27\% dos documentos há menção de que, em caso do professor apresentar algum tipo de disfonia, ser-lhe-á garantida a assistência fonoaudiológica e/ ou médica, além da preservação de seus direitos, mencionada em $9,09 \%$. 
Tabela 2. Classificação das leis, segundo tipo e natureza de ação, público alvo, iniciativa da proposição, promulgação e secretaria(s) envolvida(s) $(n=22)$

\begin{tabular}{|c|c|c|}
\hline Variável & $\mathrm{n}$ & $\%$ \\
\hline \multicolumn{3}{|l|}{ Tipo de ação } \\
\hline Cursos & 20 & 90,91 \\
\hline Orientação & 19 & 86,36 \\
\hline Palestras & 7 & 31,82 \\
\hline Avaliação & 4 & 18,18 \\
\hline Treinamento & 4 & 18,18 \\
\hline Ambiente de trabalho & 3 & 13,64 \\
\hline Direitos garantidos & 2 & 9,09 \\
\hline Assessoria & 1 & 4,55 \\
\hline Encontros & 1 & 4,55 \\
\hline Campanhas & 1 & 4,55 \\
\hline Seminários & 1 & 4,55 \\
\hline Não especifica & 1 & 4,55 \\
\hline \multicolumn{3}{|l|}{ Natureza da ação } \\
\hline Proteção/prevenção & 21 & 95,45 \\
\hline Recuperação/assistência & 17 & 77,27 \\
\hline Promoção & 2 & 9,09 \\
\hline Capacitação & 2 & 9,09 \\
\hline Não especifica & 1 & 4,55 \\
\hline \multicolumn{3}{|l|}{ Público-alvo } \\
\hline Professor/Educador & 22 & 100,0 \\
\hline Alunos & 2 & 9,09 \\
\hline Pais & 1 & 4,55 \\
\hline \multicolumn{3}{|l|}{ Iniciativa } \\
\hline Poder Legislativo & 21 & 95,45 \\
\hline Poder Executivo & 0 & 0 \\
\hline Não identificada & 1 & 4,55 \\
\hline \multicolumn{3}{|l|}{ Promulgação das leis } \\
\hline Sancionadas & 18 & 81,82 \\
\hline Vetos derrubados pelo Legislativo & 4 & 18,18 \\
\hline
\end{tabular}

Secretarias envolvidas

\begin{tabular}{lcccccc} 
& \multicolumn{2}{c}{ M e DF } & \multicolumn{2}{c}{ E } & \multicolumn{2}{c}{ Total } \\
\cline { 2 - 8 } & $\mathrm{n}$ & $\%$ & $\mathrm{n}$ & $\%$ & $\mathrm{n}$ & $\%$ \\
\cline { 2 - 7 } Saúde e Educação & 7 & 58,33 & 7 & 70,0 & 14 & 63,63 \\
Saúde & 2 & 16,67 & 0 & 0 & 2 & 9,09 \\
Adm. Rec. Hum. e Educ. & 1 & 8,33 & 0 & 0 & 1 & 4,55 \\
Saúde, Educação e Cultura & 0 & 0 & 1 & 10,0 & 1 & 4,55 \\
Não refere & 2 & 16,67 & 2 & 20,0 & 4 & 18,18 \\
\hline
\end{tabular}

Legenda: $\mathrm{M}=$ Municipal; $\mathrm{DF}=$ Distrito Federal; $\mathrm{E}=$ Estadual; Adm. Rec. Hum. e Educ. $=$ Administração, Recursos Humanos e Educação

Do conjunto de leis, apenas três delas $(13,64 \%)$ avançam para além da assistência preventiva, propondo ações mais amplas e complexas (leis estaduais e propostas pela assembléia legislativa de Pernambuco, Paraná e Minas Gerais). Entre elas pode-se citar a realização de exames admissionais e periódicos; assessoria; capacitação dos docentes com módulos sobre o uso profissional da voz e seus cuidados; reorganização do ambiente de trabalho e uso de tecnologias que favoreçam o uso da voz pelo professor; além de mencionar o afastamento por saúde e a garantia de direitos do professor que se encontra incapacitado, temporária ou indefinidamente, de exercer seu trabalho docente.

Duas das leis $(9,09 \%)$ apresentam maior abrangência, incluindo os alunos (1652/1998 e 1992/2001), sendo essa última posteriormente ampliada pela Lei Complementar 464/2002 que incluiu as ações também para os pais dos alunos. Importante lembrar que em Santos, a Lei 1781/99 cria o programa de saúde vocal, e estabelece ações de prevenção. A idéia de ampliá-lo para assistência veio com a edição da Lei 1992/01, que também estendeu o acesso do serviço para alunos. Acontece que sua edição foi equivocada, uma vez que estabeleceu a realização dos diagnósticos na escola. A Lei Complementar 464/02 exclui os artigos do texto e mantém a ampliação do programa para alunos. A Lei 1781/99 não prevê a proteção e recuperação da saúde vocal do professor, bem como inclusão desse assunto na formação do professor. Segundo informação obtida por meio dos questionários, a revisão das leis de SantosSP encontra-se em curso para adequação de seu texto.

A competência para desenvolver as ações propostas nas leis cabe, no nível municipal, à Secretaria da Saúde exclusivamente $(9,09 \%)$ ou em combinação com a Secretaria de Educação $(31,82 \%)$ e ainda uma parceria entre as Secretarias de Administração, Recursos Humanos e Educação e Gestão Pública $(4,55 \%)$, mostrando envolvimento de várias esferas do governo. No nível estadual, a integração entre Secretaria de Saúde e Educação é o que prevalece $(31,82 \%)$, equiparando-se à esfera municipal. Em 18,18\% dos documentos, municipais e estaduais, não há referência a tais dados (Tabela 2).

A iniciativa, em sua maioria, ocorreu por membros do Poder Legislativo $(95,45 \%)$, e a sanção (ato de concordância do Poder Executivo) ocorreu em 81,82\% das leis (Tabela 2).

\section{DISCUSSÃO}

Um processo iniciado na segunda metade da década de 60, principalmente na Alemanha, França, Inglaterra, Estados Unidos e Itália, contribuiu para a participação dos trabalhadores nas questões de saúde e segurança. Em resposta a esse movimento, novas políticas sociais foram transformadas em lei, e introduziram significativas mudanças na legislação do trabalho e, em especial, em aspectos referentes à saúde e segurança do trabalhador ${ }^{(21)}$.

Especificamente em nosso país, nos últimos 20 anos, a Fonoaudiologia, na área de voz, avançou fortemente nos estudos e pesquisas sobre a denominada voz profissional. Pioneiro no Brasil, o trabalho realizado em 1988 por Pinto e Fürck ${ }^{(22)}$, em forma de um projeto preventivo junto a professores da Rede Municipal de Ensino de São Paulo, denominado Saúde Vocal do Professor, atendeu 1060 professores, em grupos de até 100. Teve por objetivo atuar de maneira preventiva para diminuir a ocorrência de alterações vocais, e para tal foram realizados treinamentos, com conteúdos teóricos e práticos quanto ao adequado uso profissional da voz. As autoras relatam que, após o treinamento, cerca de $80 \%$ dos professores referiram melhor coordenação respiração-fala, falar mais calmamente, 
sem esforço e sem gritar, assim como tiveram reduzidos os sintomas de rouquidão, dores no pescoço e na nuca.

Essa proposta é aqui destacada, pois se tornou um modelo, um marco, a partir do qual outras propostas foram se constituindo, em todo o país, incorporando inclusive a terminologia saúde vocal.

Nesse mesmo ano, a promulgação da Constituição Federal introduziu uma nova perspectiva de saúde, garantida pelo Estado, e inaugurou, no Brasil, os princípios de universalidade, integralidade e equidade. Além disso, a proposta de um Sistema Único de Saúde descentralizado, no qual as ações de saúde são compartilhadas entre a União, estados e municípios, trouxe também o desafio de se definirem as responsabilidades e atribuições de cada esfera governamental, dos cidadãos e dos setores público e privado ${ }^{(23)}$.

$\mathrm{O}$ fato da totalidade das leis focalizarem o professor, em detrimento de qualquer outro trabalhador, certamente guarda relação com o grande número dessa natureza de profissionais no Brasil (http://www.inep.gov.br/estatisticas/professor2003/), e consequentemente, dentre os chamados profissionais da voz.

A iniciativa de colaborar para a saúde do professor foi maior em nível municipal (50\%), no entanto, com frequência bastante similar, observam-se propostas estaduais $(45,45 \%)$, as quais têm maior área de abrangência. Uma justificativa plausível relaciona-se ao interesse político dessas prefeituras em desenvolver seus programas de saúde vocal, pelo fato de viverem concretamente a problemática dos atestados e dos afastamentos desses profissionais devido a questões de saúde e voz. Outra justifica cabível encontra-se no fato de que a pressão popular para a discussão e aprovação dessas leis de saúde vocal ocorre de forma mais intensa junto a vereadores do que deputados, pela proximidade dos primeiros junto à comunidade.

A indicação de realização de um curso teórico-prático anual, mais frequente nas leis, significa um grande avanço no apoio ao professor. Essa iniciativa, porém não pode contemplar apenas as questões referentes aos cuidados com a voz. Os participantes precisam ser trabalhados com a voz como expressividade, e perceber a riqueza de efeitos gerados na utilização de diferentes recursos fônicos na interlocução com as pessoas, na tentativa de adequar ao contexto em que cada um está inserido. O fonoaudiólogo conduzirá o profissional a perceber os fatores psicossociais implícitos na produção vocal, marcados pela personalidade, pelo estado emocional, e presentes nas relações interpessoais ${ }^{(1)}$.

Entre as leis analisadas há, ainda, menção de um curso específico para professores que ingressam na profissão, fato que garante que o professor se aposse de tecnologias que possam protegê-los de problemas vocais e tenha melhores condições de seguir sua carreira de forma duradoura.

As leis de saúde vocal, de modo geral, apresentam texto genérico e terminologia distinta daquela da área fonoaudiológica e médica, relativas às ações que devem ser implementadas. A consideração de que se trata de uma questão relativa à saúde de um segmento profissional, remete ao Sistema Único de Saúde que, por definição, preconiza que os municípios gerenciem suas demandas. Desta forma, mesmo que a necessidade nasça da área de educação, a parceria com a saúde se faz premente, uma vez que é ela o setor que abriga em suas equipes tanto o profissional fonoaudiólogo quanto o médico que poderão oferecer ações educativas, preventivas e/ou curativas na área de saúde vocal do professor.

As leis analisadas indicam uma ação conjunta e de interesse tanto da população em geral quanto dos professores, que é o trabalho integrado da educação e saúde, áreas que, embora mantenham estreita interface, ainda trabalham de forma isolada na gestão e desenvolvimento de ações. Esta iniciativa das leis de saúde vocal aproxima estrategicamente essas duas áreas, em direção ao que a Organização Pan-americana de Saúde denomina de escolas promotoras de saúde ${ }^{(24)}$.

A idéia de escolas promotoras de saúde é que a instituição escolar seja também um espaço educativo para a saúde, no cultivo de estilos de vida saudáveis, com repercussão para alunos e comunidade. Desta forma, professores também estarão sendo cuidados e capacitados para essa nova proposta. Dentro do escopo da saúde, a voz ocupa lugar importante, tanto para professores quanto para alunos e deve ser preservada e aperfeiçoada ${ }^{(25)}$.

Outra questão importante é que as leis determinam que o fonoaudiólogo seja o profissional responsável pela condução do processo de capacitação docente quanto ao uso profissional da voz pelo professor. Isso abre inúmeras possibilidades de ações de promoção, proteção e recuperação da voz. Por outro lado, abre perspectivas de assessoria para desenvolver a expressividade docente e colaborar para o avanço do processo ensino-aprendizagem.

O fato do fonoaudiólogo responsável pela condução desse processo ter o status de servidor da secretaria da saúde o compromete, a partir do seu engajamento, a cuidar da voz do professor, tanto nos aspectos de promoção da saúde como na prevenção da doença, mencionados anteriormente. Leva-o, ainda, a atuar para que se criem condições de acesso dos docentes à terapia fonoaudiológica nos Serviços de Fonoaudiologia, de modo a superar distúrbios instalados, inclusive nas situações emergenciais, para que o professor não tenha que deixar a sala de aula e comprometer seu trabalho. Para tanto, a organização do Serviço deve prever tal demanda e dispor de recursos humanos para sua absorção.

É importante destacar que toda vez que o Poder Executivo veta um projeto de lei ou partes dele, este veto é analisado pelo Legislativo que, em derrubando-o, encaminha o projeto, não mais para sanção, mas sim para a promulgação (ato de se fazer conhecer a Lei). Caso o chefe do Poder Executivo não promulgue a lei, esse ato deve ser feito pelo chefe do Poder Legislativo.

Apesar de haver somente quatro vetos $(18,18 \%)$, a maioria das iniciativas foi do Poder Legislativo $(95,95 \%)$, o que se constitui como entrave para a implementação de um programa de saúde vocal. O Legislativo não tem competência para iniciar o trâmite de projetos de lei que levem ao aumento de gastos do Executivo (Art. 61 da Constituição da República). Portanto, os programas instituídos por leis cujos projetos tiveram iniciativa pelo Legislativo são inconstitucionais por gerarem gastos em outro poder.

Por outro lado, o Poder Legislativo pode instituir tais projetos ou autorizar o Executivo a instituí-los, mudando-se 
a redação para que apenas permita a sua realização. Contudo, uma lei permissiva não tem tanta assertividade como uma lei com maiores obrigações; vale como força política, para sinalização dos intentos dos cidadãos.

A decisão mais importante, assim, continua nas mãos do Chefe do Executivo, Governador ou Prefeito. Não se pode dizer que o trabalho de criar leis por iniciativa do Legislativo seja vão, entretanto, porque no jogo político as leis têm bastante relevância, podendo levar um Executivo vacilante a optar pela implementação dos projetos de saúde vocal.

Considerando suas grandes contribuições para essa área, o fonoaudiólogo ou órgão representativo poderiam assessorar o Legislativo quanto à terminologia e ações apropriadas competentes neste campo facilitando a implementação de leis e sua execução. O esforço coletivo de fonoaudiólogos e professore junto ao Poder Legislativo e também ao Executivo, constituemse ferramentas essenciais para viabilização de programas de saúde vocal do professor.

\section{CONCLUSÃO}

Conclui-se que, pelo grande número de casas legislativas brasileiras e pelas consequências negativas, advindas do afastamento do trabalho por professores devido a alterações vocais, tanto para a Educação quanto para os cofres públicos, a quantidade de leis em favor da saúde vocal desse profissional ainda é incipiente.

Apesar dos avanços obtidos, enquanto a saúde vocal não for tratada pelos chefes dos Poderes Executivos como assunto de interesse, as iniciativas legislativas continuarão ineficazes por serem consideradas inconstitucionais. Do mesmo modo, os recursos humanos e financeiros necessários para o desenvolvimento das ações propostas nas leis existentes podem não ser garantidos, inviabilizando assim a implantação e consolidação desses programas.

\begin{abstract}
Purpose: To characterize legislation related to vocal health published in National Territory until the year of 2006 . Methods: A documentation search was carried out in official websites. In addition, a questionnaire developed by the authors was distributed by e-mail to Speech Therapists so that the greatest possible number of laws was gathered. The 22 documents obtained were analyzed considering their area-inclusion radius, proposed actions and their natures, target population, public offices involved, initiative and law promulgation. An absolute (numerical) and a relative (percentage) analysis were carried out. Results: The documents found are mainly state laws, mostly from the Southeast region, proposed by the Legislative branch. Their feasibility lies within partnerships of State health and education offices. In general, the proposals proclaim the implementation of preventive assistance models through annual theoretical and practical classes $(90.91 \%)$ ministered by Speech Therapists, with exception of those teachers with vocal disorders, who will have access to speech therapy and/or medical treatment $(77.27 \%)$. Only three documents (13.64\%) go beyond the classes mentioned above, with the proposal of actions that span from health promotion to rehabilitation, including references to work environments. Two of them $(9.09 \%)$ consider the rights of the working teachers. Conclusion: Given the great number of legislative houses in Brazil, there are few laws that aim towards teachers' health, especially regarding their voice. Moreover, to make sure that these laws are applied and implemented as vocal health programs, these initiatives should be proposed by the National Constitution, so that the necessary resources for their viability are guaranteed.
\end{abstract}

Keywords: Faculty; Laws; Health promotion; Disease prevention; Health public policy; Legislation, health; Legislation

\title{
REFERÊNCIAS
}

1. Ferreira LP. Assessoria fonoaudiológica aos profissionais da voz. In: Ferreira LP, Befi-Lopes DM, Limongi SCO, organizadores. Tratado de fonoaudiologia. São Paulo: Roca; 2004. p. 138-49.

2. Viola IC, Ferreira LP, Sene CD, Villas Boas DC, Souza SM. A voz do professor: levantamento das publicações brasileiras. Rev Soc Bras Fonoaudiol. 2000;1(1):36-47.

3. Dragone MLS, Behlau M. A fonoaudiologia brasileira e a voz do professor - olhares científicos no decorrer do tempo. Fonoaudiol Brasil. 2006;4(2):6-9.

4. Ferreira LP, Migliorini D.R. Fonoaudiologia e telemarketing: como tudo começou. In: Alloza RG, Salzstein RBW. Fonoaudiologia na empresa: atuação em Call Center. Rio de Janeiro: Revinter; c2002. p. 1-8.

5. Silvany Neto AM, Araújo TM, Dultra FRD, Azi GR, Alves RL, Kavalkievick C, Reis EJFB. Condições de trabalho e saúde de professores da rede particular de ensino de Salvador, BA. Rev Baiana Saúde Pública. 2000;24(1/2):42-56.
6. Masson MLV. Professor, como está sua voz? Distúrb Comun. 2001;13(1):175-80.

7. Simões M, Latorre MRDO. Alteração vocal em professores: uma revisão. J Bras Fonoaudiol. 2002;3(11):127-34.

8. Ferreira LP, Giannini SPP, Figueira S, Silva EE, Karmann DF, Souza TMT. Condições de produção vocal de professores da Prefeitura do Município de São Paulo. Distúrb Comun. 2003;14(2):275-307

9. Delcor NS, Araújo TM, Reis EJBF, Porto LA, Carvalho FM, Silva MO, et al. Condições de trabalho e saúde dos professores da rede particular de ensino de Vitória da Conquista, Bahia, Brasil. Cad Saúde Pública = Rep Public Health. 2004;20(1):187-96.

10. Servilha EAM. Estresse em professores universitários na área de fonoaudiologia. Rev Ciênc Méd. 2005;14(1):43-52.

11. Yiu EM. Impact and prevention of voice problems in the teaching profession: embracing the consumers' view. J Voice. 2002;16(2):21528. 
12. Skarlatos D, Manatakis M. Effects of classroom noise on students and teachers in Greece. Percept Mot Skills. 2003;96(2):539-44.

13. Roy N, Merrill RM, Thibeault S, Parsa RA, Gray SD, Smith EM. Prevalence of voice disorders in teachers and the general population. J Speech Lang Hear Res. 2004;47(2):281-93.

14. Simberg S, Sala E, Vehmas K, Laine A. Changes in the prevalence of vocal symptoms among teachers during a twelve-year period. J Voice. 2005;19(1):95-102.

15. Sliwinska-Kowalska M, Niebudek-Bogusz E, Fiszer M, Los-Spychalska T, Kotylo P, Sznurowska-Przygocka B, Modrzewska M. The prevalence and risk factors for occupational voice disorders in teachers. Folia Phoniatr Logop. 2006;58(2):85-101.

16. Preciado J, Pérez C, Calzada M, Preciado P. [Prevalence and incidence studies of voice disorders among teaching staff of La Rioja, Spain. Clinical study: questionnaire, function vocal examination, acoustic analysis and videolaryngostroboscopy]. Acta Otorrinolaringol Esp. 2005;56(5):202-10. Spanish.

17. Salas Sánchez WA, Centeno Huamán J, Landa Contreras E, Amaya Chunga JM, Benites Galvez MR. Prevalencia de disfonía en profesores del distrito de Pampas - Tayacaja - Huancavelica. Rev Med Hered. 2004;15(3):125-30.
18. Centro de Vigilância em Saúde. Distúrbios da voz relacionados ao trabalho. Boletim Epidemiológico Paulista [Internet]. 2006;3(26). [citado 2007 Jun 10]. Disponível em: http://www.cve.saude.sp.gov.br/ agencia/bepa26_dist.htm

19. Boone DR. Inimigos biológicos da voz profissional. Pró-Fono. 1992;4(2):3-8.

20. Penteado RZ, Servilha EAM. Fonoaudiologia em saúde pública/coletiva: compreendendo prevenção e o paradigma da promoção de saúde. Distúrb Comun. 2004;16(1):107-16.

21. Mendes R, Dias EC. Da medicina do trabalho à saúde do trabalhador. Rev Saúde Pública = J Public Health. 1991;25(5):341-9.

22. Pinto AMM, Furck MAE. Projeto saúde vocal do professor. In: Ferreira LP, organizador. Trabalhando a voz: vários enfoque em fonoaudiologia. São Paulo: Summus; 1988. p 11-27.

23. Castro JD. Regulação em saúde: análise de conceitos fundamentais. Sociologias. 2002;4(7):122-35.

24. Organização Pan-Americana da Saúde. Escuelas promotoras de la salud: modelo y guía para la acción. HSP/SILOS-36. Washington, D.C; OPAS: 1996.

25. Penteado RZ. Escolas promotoras de saúde: implicações para a ação fonoaudiológica. Fonoaudiol Brasil. 2002;2(1):28-37. 